\title{
The Medical Effects of Seat-Belt Legislation in the United Kingdom: one viewpoint from the USA
}

\author{
ELAINE PETRUCELLI \\ American Association for Automotive Medicine, Illinois, USA
}

Britain introduced a belt-use law in July 1981 to become effective on 31 January 1983, a full 13 years after Australia. In the USA, priority was given to laws requiring infants and young children to be appropriately restrained so that between 1977 and 1984 all 50 states and the District of Colombia enacted child passenger safety laws. It was not until 12 July 1984 that New York became the first USA state to introduce mandatory use of seat-belts by all front-seat occupants beginning 1 December 1984.

The New York campaign for a belt-use law began in the spring of 1982 with establishment in November of that year of a state coalition representing medicine, business, education, state agencies and community service groups. The British experience became an integral part of the ammunition in the legislative debate as well as in maintaining media interest in the subject.

In New York, as of 1 December 1984, all drivers, front-seat passengers and children in the rear seat up to the age of 10 have been required to buckle up. The driver is responsible for occupanto under age of 16. The law permits exemptions for drivers of buses, taxis, liveries, emergencen vehicles and large commercial trucks over 18000 pounds gross vehicle weight. Passengers of school buses are not required to use belts, although school bus drivers are covered by a previous statute. Exemptions are allowed for some medical conditions if certified by a physician following an examination of the patient. However, the Medical Society of the State of New York declined to approve guidelines for granting medical exemptions which had been drawn up by the State Health Department and the Governor's Traffic Safety Committee, Department of Motor Vehicles, on the basis that no medical contra-indications to belt use have as yet presented themselves. The Medical Society stated that 'the danger of not wearing a belt outweighs the risks involved in every case so far considered'. Potential physician liability for damages should an exempted patient later be involved in an injury-producing crash was also an issue.

Pre-law observational surveys conducted in October 1984 showed belt-use to be $16 \%$. In December 1984 when the law went into effect with a one-month warning period, usage increased to $43 \%$ for drivers and $38 \%$ for front-seat passengers. During the first full month of the law with citations being issued usage increased to $75 \%$ for drivers and $67 \%$ for front-seat passengers. Beltuse counts for the 6-month period from January to June 1985 indicate that use has probably levelled off at about $\mathbf{5 7 \%}$ which is three and a half times higher than pre-law usage. The current level of use, while not satisfactory, was not unexpected given similar experiences of several Canadian provinces in closer proximity to New York State than Great Britain.

Occupant fatalities in New York State have decreased by 18\% during the first 6 months of 1985 as compared to the same period in 1984 (from 535 to 438). Compared to the previous 5-year average for January-June, occupant fatalities have dropped by $28 \%$ (from 608 to 438 ).

The study on the medical effects of seat-belt legislation in the United Kingdom is a major contribution to understanding the relationship between a mandatory belt-use law and motor-

Correspondence: Ms Elaine Petrucelli, American Association for Automotive Medicine, Arlington Heights, II, Illinois, USA 
vehicle-related trauma. The report clearly states its purpose to be an investigation of the changes in incidence, severity and patterns of injury based upon hospital casualty information. The report makes no claims that cannot be supported by its findings and acknowledges the limitations of the study.

The findings of the study contain a number of implications for the USA in both pre-law and post-law states as well as at the national level.

Firstly, the findings of the study as related to reductions in emergency room visits (15\%), hospital admissions (25\%) and bed occupancy $(25 \%)$, and in multiplicity of injuries are of major importance in terms of the increasing costs of medical care. In the USA, about $10 \%$ of the nation's GNP is related to the delivery of the country's health care system.

Secondly, while the study was not specifically addressing the $90+\%$ usage, its findings must be viewed in the light of this high compliance with the law. It is not possible to make direct comparisons between the UK, where voluntary use was about $40 \%$ at the time the law was introduced, and any one of the United States, where use has never reached $20 \%$ just prior to passage. Furthermore, no state in the USA has yet come close to the UK's $90 \%$ post-law usage. What does tempt the imagination, however, is the level of injury reductions that might be achieved in the USA at a $90 \%$ usage when starting between 15 and $20 \%$ voluntary use.

Thirdly, the study's documented reductions in incidence and severity of injuries should provide a buffer against serious repeal efforts in the earliest states with seat-belt laws, especially until these states are able to establish their own data bases on injuries.

Fourthly, the findings that over a wide range of injuries, both drivers and front-seat passengers have accrued considerable benefits but the latter enjoyed the greater improvement is especially noteworthy. Usage data from New York show that the front-seat passenger is somewhat less likely to buckle up than the driver. It seems appropriate that information and education programmes should be reassessed for this sub-population of motor vehicle occupants, especially if this trend continues in other states with belt-use laws.

The findings related to rear-seat passengers are equally important. No state yet requires rearseat occupants to buckle up, although the issue has been considered in several legislative sessions. This report may provide some impetus for a state or two to introduce a universal use law, or for an existing law to be amended appropriately in the near future.

Fifthly, the study report provides welcome support for efforts in the USA to influence funding of adequate evaluation based on hospital injury data to measure the consequences of belt-use laws.

If the report suffers from any deficiency, it is the lack of information on crash severity. The inclusion of police-reported information, as originally proposed but eventually abandoned, could have provided the dimension of collision type and severity that is fundamental to understanding crash dynamics and the biomechanics of occupant injury. In fact, the finding that the number of drivers with major brain injury increased, although not statistically significant, could well be a function of crash severity as well as the anticipated consequence documented in earlier studies of restrained drivers having head contacts with steering wheels rather than life-threatening chest contacts if unrestrained. The unsophisticated reader who only scans the report's major findings may reach the erroneous conclusion that drivers are worse off when belted in crashes than unbelted when in fact the pattern of injury and not necessarily the severity has been altered.

A second finding that should be treated carefully is the increase in abdominal organ injuries, except the kidney, although again not statistically significant. In the USA even with inertia reel seat-belts, a relatively high level of incorrect belt-use is suspected. The same situation may exist in Britain.

Among minor (AIS-I) injuries, the increase in neck strains, although not unexpected among restrained occupants especially in relatively severe crashes, is probably the most important aspect. The suggestion that these types of cervical spine injuries may be under-represented is also not 
surprising given that the symptoms may not manifest themselves for up to 24 hours following the event, and might, therefore, not be captured in official injury records. The documented increase in minor neck strains may well be the 'trade-off' in restrained occupants of life-threatening or ? fatal trauma if unrestrained. It is also quite likely that-given the circumstances of the study and $\overrightarrow{\vec{S}}$ the level of sophistication of the hospital data acquisition, more intensive diagnoses were made to uncover all injuries. There is question as to whether the increase in minor neck strains is absolute or whether it is a function of better reporting procedures.

(1) 